\title{
DEMOCRACIA E TOLERÂNCIA À SUBORDINAÇÃO: LIVRE-ESCOLHA E CONSENTIMENTO NA TEORIA POLÍTICAFEMINISTA
}

\author{
Flávia Biroli
}

RESUMO

O artigo apresenta e analisa críticas feministas à acomodação entre a valorização liberal da livre-escolha dos indivíduos e as desigualdades materiais e simbólicas que restringem a autonomia individual. O foco da análise apresentada é, primeiramente, a crítica à noção de consentimento voluntário que é base fundamental para o liberalismo. Para expor a insuficiência da dualidade liberal entre coerção e livre-escolha para a análise das fronteiras entre consentimento voluntário e recusa, o artigo discute as relações entre consentimento e estupro. Torna-se possível, assim, analisar as conexões entre o consentimento na vida cotidiana e o consentimento no estado liberal-democrático, tomando como ponto de partida as relações de gênero e as formas de vulnerabilidade associadas à posição social das mulheres. O resultado é o deslocamento do foco da análise, do caráter voluntário da expressão de uma preferência ou da realização de uma escolha, para uma abordagem orientada pela autodeterminação como valor prioritário para a democracia. São destacados dois conjuntos de problemas: aqueles que emergem das situações nas quais a diferença entre consentimento e não-consentimento é anulada - e, com ela, a condição de agentes morais daquelas que consentem ou deixam de consentir - e aqueles que são expostos pela análise das situações em que há consentimento, mas este conduz à subordinação ou reforça a vulnerabilidade do próprio indivíduo.

PALAVRAS-CHAVE: consentimento; livre-escolha; estupro; preferências; teoria politica feminista.

\section{INTRODUÇÃO}

Um problema atravessa as abordagens feministas, ainda que elas confrontem-no de maneiras distintas: a existência de direitos formalmente iguais não é suficiente para situar os indivíduos igualmente no que diz respeito às possibilidades efetivas de autodeterminação ${ }^{1}$. As relações de poder, que incluem variações da tolerância social à subordinação, são expressas em formas legitimadas de autoridade, em

\footnotetext{
${ }^{1}$ As discussões apresentadas neste artigo integram as pesquisas "Desigualdades e preferências: a tensão entre o valor da autonomia individual e a crítica à opressão na teoria política contemporânea", financiada pelo CNPq, e "Justiça, democracia e desigualdades: entrelaçamentos teóricos, implicações práticas" (CNPq, edital n. 7/2011). Uma versão anterior e reduzida deste texto foi apresentada no IV Simpósio de Teoria Política do IFCS-UFRJ, realizado na Universidade Federal do Rio de Janeiro (UFRJ) em setembro de 2012. Foi, tambem, discutida no Grupo de Pesquisa sobre Democracia e Desigualdades, o Demodê, da Universidade e Brasília (UnB). Agradeço às/aos colegas que participaram do Simpósio, aos integrantes do Demodê, e às/aos pareceristas anônimos da Revista de Sociologia e Política pelas contribuições. Agradeço, em especial, a Luis Felipe Miguel pelos comentários feitos a versões anteriores do texto.
}

expectativas sociais relativas ao papel que mulheres e homens desempenhariam nas diferentes esferas e, sobretudo, no modo como as posições sociais estão associadas a recursos simbólicos e materiais - e como definem o acesso a eles.

Considerado esse solo comum, o debate sobre autonomia e preferências no feminismo é fecundo justamente em suas ambiguidades. Elas expõem as tensões entre a valorização da capacidade dos indivíduos de expressar autonomamente suas preferências, e a crítica, necessária, ao fato de que as preferências são desdobramentos das relações de poder. Por isso, ao discutir a formação das preferências e as possibilidades de escolhas autônomas, o debate feminista remete sistematicamente à posição social dos indivíduos e não a processos e cálculos mentais individuais que se dariam em uma esfera à parte interna ou mais autêntica.

Em uma breve definição, pode-se dizer que contexto e processo são o objeto nas análises assim orientadas. De modo preliminar, defino o contexto como o conjunto das regras legais, das pressões sociais, das informações e recursos materiais disponíveis, dos valores mobilizados no cotidiano da "cultura" (SUNSTEIN, 2009), dos hábitos 
naturalizados e das práticas que se repetem rotineiramente. $\mathrm{O}$ processo em que as preferências são produzidas pode ser entendido, ainda preliminarmente, como a interação variável entre esses fatores ao longo do tempo, mas também segundo a posição ocupada em uma sociedade por diferentes indivíduos e grupos. São variações e combinações que se definem diacrônica e sincronicamente. Assim pensados, os determinantes das preferências não são tomados como algo estanque, mas também não correspondem à ideia de que haveria uma "evolução" a partir de uma única matriz. Por isso, é possível verificar a convivência entre deslocamentos e reposição de valores convencionais na base das preferências, e das escolhas que poderão delas desdobrar-se, em um dado momento. Nos países ocidentais, as mudanças na posição social da mulher expõem a convivência entre deslocamentos e reposição das convenções. Elas enfraquecem valores e práticas fundados na ideia de subserviência "natural" das mulheres aos homens, o que tem impacto na formação de suas preferências. As alternativas disponíveis e os valores e expectativas sociais impactam, conjuntamente, preferências e escolhas. São muitas, no entanto, as formas de reposição de definições convencionais do feminino e das hierarquias de gênero. Um exemplo significativo é o investimento de tempo e de recursos financeiros na aparência, como no caso das cirurgias plásticas de todo tipo, que tornariam as mulheres mais atraentes e permanentemente jovens ${ }^{2}$. Pode ser tomado como uma demonstração de que a valorização da domesticidade feminina ficou para trás, mas deu lugar a uma domesticação por meio de padrões de comportamento orientados por ideais relativos à aparência, que estão na base de preferências que permitem que o trabalho de coerção social seja reposto, ainda que em outros termos (WOLF, 2002, p. 14).

A constatação do caráter social das preferências e tendências individuais define um campo para a análise dos problemas relativos à produção das preferências nas sociedades contemporâneas. As preferências, inclusive quando enunciadas como escolhas, conduzem-nos diretamente à análise do contexto de sua produção e, assim, aos incentivos e constrangimentos presentes no processo em que essas preferências definiram-se, aos recursos e alternativas disponíveis. Há uma relação importante entre as preferências e as escolhas dos indivíduos, que faz com que existam conexões entre o processo de formação das preferências, as escolhas "livremente" feitas pelos

\footnotetext{
2 Para análises específicas da relação entre dominação, beleza e cirurgias plásticas, com abordagens distintas, conferir Black (2004) e Jeffrey (2005).
}

indivíduos e a democracia como autogoverno. A formação autônoma das preferências e dos interesses é fundamental para a democracia, se esta é tomada como algo além dos procedimentos para a escolha dos governantes.

A ampliação das condições para a livre-escolha acompanha, no pensamento e nas instituições modernas, a visão utilitarista de que os indivíduos são os melhores juízes naquilo que concerne a sua própria vida. O respeito aos indivíduos em sua capacidade de definir o que é melhor para si corresponderia a tomar as escolhas (i) como expressão das suas preferências, quando não há interferência ou coerção e (ii) como escolhas legítimas porque "autênticas", isto é, fundadas nas preferências livremente expressas de indivíduos livres. Em um desdobramento dessa concepção, no igualitarismo liberal contemporâneo a relação entre igualdade e respeito às diferentes concepções de bem está, também, associada à compreensão de que os indivíduos são responsáveis pela vida que escolhem viver (PHILLIPS, 1999; 2006; DWORKIN, R., 2005; YOUNG, 2011; BIROLI, 2012b).

As teorias da escolha racional avançam ainda mais em uma caracterização das escolhas dos indivíduos que opera com a noção de livre-escolha de um modo que ofusca o caráter social da formação das preferências. Este artigo não pretende discuti-las ou analisar de que modo as diferentes abordagens nessa corrente destacam os fatores e condicionantes nas escolhas dos agentes. Apenas a título de exemplo de como se dá essa sublimação do problema da formação das preferências, recorro a uma análise que faz parte das discussões de Jon Elster em Ulysses unbound (ELSTER, 2000). Trata-se, como se sabe, de uma versão sofisticada das teorias da escolha racional, que expõe a complexidade dos fatores que definem as escolhas dos indivíduos e uma série de matizes e contradições na própria noção de racionalidade individual.

Retomando análises anteriores, Elster volta-se para situações nas quais as pessoas, contradizendo a visão comum de que é sempre melhor ter mais opções do que menos, optam por restringir as informações e opções disponíveis ${ }^{3}$. Entre os casos considerados estão, as ações por meio das quais os indivíduos

\footnotetext{
3 Nesse livro, Elster recoloca as discussões feitas em Ulysses and the Sirens, de 1979, e Sour Grapes, de 1983. Seu enfoque retoma a análise de Ulisses amarrado ao mastro de seu navio: remete à busca, pelos próprios indivíduos, de restringir as opções disponíveis quando entendem que isso, de algum modo, os beneficiaria. É um dilema distinto daquele que se coloca em Sour Grapes, a partir da fábula "A raposa e as uvas" (La Fontaine), quando o foco está nas preferências adaptativas.
} 
buscam restringir sua liberdade de escolha, assim como a de outros membros de sua comunidade, para evitar a assimilação cultural ou religiosa. Esse seria o caso dos Amish, comunidade cristã anabatista, presente nos Estados Unidos e no Canadá, que tem como uma de suas principais características a recusa a uma série de recursos e confortos modernos. Em um dos exemplos dados, Elster descreve as decisões na Suprema Corte Americana, em 1971, relativas ao julgamento de três famílias Amish por não permitirem que seus filhos frequentassem a escola pública após o oitavo ano. O depoimento de Frieda, uma criança que ao longo do julgamento responde afirmativamente ao ser questionada se a religião dela era "a única razão pela qual ela não ia à escola" naquele momento, é assim analisado por Elster: "Nós podemos duvidar que a crença de Frieda de que mais dois anos na escola pública seriam uma 'exposição inadmissível a uma influência mundana em conflito com suas crenças' seja de fato autônoma. É mais provável, talvez, que seu medo dos efeitos da pressão dos pares tenha sido definido pela influência dos pais. Do ponto de vista dessa análise, no entanto, essa questão é irrelevante. Tudo o que importa é que Frieda expressou o desejo de permanecer ignorante em relação ao mundo moderno, e que a lei (ou pelo menos o Juiz Douglas) decidiu respeitar esse desejo" (idem, p. 60).

A causa imediata dessa opção por restringir as próprias informações e influências seria o que Elster denomina "autopaternalismo", entendido como uma forma de autopreservação do indivíduo em relação a preferências consideradas de menor valor do que as atuais, que poderia vir a assumir caso as restrições não existissem. Em uma terminologia importante para esta discussão, o que importa é que Frieda expressou seu livre consentimento - ainda que em sua origem esteja a autoridade dos pais e de sua comunidade religiosa.

Considerando que a resposta afirmativa de Frieda seja autônoma, no sentido de que não resulta de coerção baseada em violência ou ameaça de violência - o que penso ser difícil de sustentar, neste caso, porque em relações familiares tradicionais não há um limite claro entre autoridade e formas de constrangimento e de violência -, restaria pelo menos

Nesse caso, o imperativo é "reduzir as ambições, adequar-se a um horizonte limitado de possibilidades e adaptar suas preferências diante de circunstâncias que elas [as pessoas] não controlam" (MIGUEL, 2012c, p. 4), o que estaria muito mais próximo de como se define o problema da relação entre escolhas e preferências no mundo social (MIGUEL, 2013) e mais próximo também dos problemas colocados pelas abordagens feministas discutidas neste artigo. um problema central, que é a análise das condições para a autodeterminação individual, assim como para o livre consentimento, em comunidades nas quais a manutenção dos costumes e das crenças do grupo é colocada acima da liberdade dos indivíduos ${ }^{4}$. As formas de controle que restringem a autonomia no processo de formação das preferências de Frieda no caso, fundadas na religião e no exercício da autoridade pelas hierarquias que organizam sua comunidade - não são uma questão na abordagem de Elster. Do mesmo modo, as consequências da escolha baseada nessas preferências estão fora do âmbito da análise - mesmo que elas sejam voltas a mais nos parafusos que restringem alternativas e recursos que dariam, a Frieda, condições efetivas de autodeterminação.

Ao mesmo tempo que, na abordagem de que faz parte o caso dos Amish, Elster amplia a complexidade no entendimento das motivações dos indivíduos ao agir, as relações entre os indivíduos praticamente desaparecem, ou deixam de ter relevância para as questões que são colocadas. Meu ponto é que o foco na expressão do desejo, na escolha ou no consentimento, obscurece, em vez de esclarecer, o que está em jogo.

Ao questionar os pressupostos das análises baseadas na universalidade da razão e na efetividade da igual liberdade dos indivíduos, o feminismo colabora para que se perceba que a narrativa baseada na ideia de que "muito do progresso na história humana se desenhou [...] como remoção de restrições legais ou materiais à escolha" (ELSTER, 2000, p. 1) é, para dizer o mínimo, apenas uma parte da história. As escolhas dos indivíduos podem: $(i)$ remeter a hierarquias e a formas de opressão internas ao grupo; (ii) remeter à carência e à precariedade; (iii) produzir subserviência e/ou impedimentos à autodeterminação.

No primeiro caso, a escolha pode ser fundamentada por preferências, mas é difícil sustentar que estas tenham sido autonomamente produzidas. Pode, também, fundamentar-se na ausência de alternativas que permitiriam opor-se às hierarquias $\mathrm{e}$ formas de autoridade existentes, mesmo quando existam preferências que conduziriam a escolhas distintas. É esse primeiro caso que corresponde ao exemplo dos Amish, dado a partir de Elster.

No segundo caso, as escolhas podem ser livres, no sentido de que não são coagidas, mas isso não é suficiente para que sejam tomadas como a manifestação

\footnotetext{
4 A esse respeito, conferir as discussões em Kymlicka (1995; 2007), Okin (1999), Sunstein (1999) e Phillips (2007; 2010).
} 
de preferências. Manifestam a ausência de alternativas, a vulnerabilidade. E no terceiro, a livre-escolha apresenta outro aspecto, que remete aos seus desdobramentos: ela restringe a autonomia. Somos colocados diante do problema da crítica às escolhas que levam à subordinação ou restringem o domínio dos indivíduos sobre si mesmos.

Nos três casos, o foco na escolha está atrelado normativamente à ausência de coerção. Ao mesmo tempo, o problema das restrições à autonomia - no processo em que as preferências definem-se, na efetivação da escolha e em suas consequencias permanece obscuro.

As abordagens sobre autonomia e preferências na teoria política feminista variam bastante. Algumas se situam a partir do entendimento, predominante no liberalismo, da autonomia como ausência de coerções. Abordagens como as de Cornell (1998) e Okin (1999) podem ser aqui posicionadas, ainda que preservem as tensões entre a crítica feminista à dualidade entre o público e o privado e os valores liberais 5 . Em outras, que se afastam mais acentuadamente dos pressupostos liberais, a crítica aos limites à efetividade da autonomia individual é associada à valorização das interações e da interdependência, do cuidado e, em alguns casos, dos afetos, promovendo, no limite, um afastamento em relação ao próprio valor da autonomia. As abordagens identificadas como maternais, mas também aquelas que procuram destacar os problemas relativos à dependência, podem ser aqui situadas Elshtain (1981), Fineman (2004) e os textos reunidos por Held (1995) são exemplos importantes.

As abordagens que serão aqui discutidas distinguem-se tanto das primeiras quanto das últimas. Elaboram críticas contundentes à dualidade entre autonomia e coerção, mas mantêm o valor da autonomia. Seu foco são os limites à formação autônoma das preferências e ao exercício efetivo da autonomia em contextos nos quais há desigualdades e assimetrias relevantes no acesso a recursos. Ao problematizar a acomodação entre livre-escolha e restrições à autonomia individual, deslocam o foco da análise do caráter voluntário da expressão de uma preferência ou da realização de uma escolha para uma análise orientada pela autodeterminação como valor prioritário para a democracia. As autoras aqui destacadas, Carole Pateman e Catharine Mackinnon, compartilham essa crítica, mas assumem, a partir dela, posições distintas, como se verá.

\footnotetext{
5 Para uma análise da posição de Susan Okin, focada justamente nas continuidades e tensões entre feminismo e liberalismo, conferir Biroli (2010).
}

O ponto de partida das reflexões aqui apresentadas é a crítica à noção de consentimento 6 . $\mathrm{O}$ artigo dividese em três seções, além desta introdução e da conclusão. A primeira apresenta a crítica à noção de consentimento voluntário como base fundamental para o liberalismo. A segunda seção analisa as conexões entre o consentimento na vida cotidiana e o consentimento no estado liberal-democrático, tomando como ponto de partida as relações de gênero e as formas de vulnerabilidade associadas à posição social das mulheres. Para expor a insuficiência da dualidade entre coerção e livre-escolha para a análise das fronteiras entre consentimento voluntário e recusa, a terceira seção, por sua vez, discute as relações entre consentimento e estupro. Destaca-se dois conjuntos de problemas, a partir de duas situações: na primeira, há anulação do não-consentimento; na segunda, o consentimento é fruto da ausência de alternativas ou conduz à subordinação. Por fim, uma breve conclusão retoma a relação entre assimetria de recursos, formação das preferências e livre-escolha, afirmando uma compreensão da democracia que requer a desnaturalização da subordinação.

\section{CONSENTIMENTO VOLUNTÁRIO E SUBORDI- NAÇÃO NO LIBERALISMO}

As análises da noção de consentimento que está na base do pensamento e das instituições liberais colocam uma questão fundamental: "em que medida o consentimento genuíno é possível nos limites das instituições do estado liberal-democrático" (PATEMAN, 1989, p. 71). Dada a compreensão desses limites pelas autoras que mobilizo mais sistematicamente para essa discussão, a cientista política inglesa Carole Pateman e a jurista estadunidense Catharine MacKinnon, a questão é se há consentimento genuíno, autonomamente definido, quando as preferências e as escolhas definem-se em contextos assimétricos, em meio a relações de opressão e dominação. A distinção entre consentimento voluntário, consentimento tácito, aquiescência e recusa torna-se, então, fundamental.

Há um deslocamento em relação ao foco na livreescolha, como dito anterioremente. Na análise dos contratos que envolvem a propriedade na pessoa especialmente o contrato de trabalho e o contrato de casamento -, Pateman (1989) tem como preocupação

\footnotetext{
6 Em outros momentos, o foco das análises realizadas no âmbito dessa mesma pesquisa foi o contraponto entre análises procedimentais e substantivas da autonomia (BIROLI, 2012a), a relação entre autonomia, experiências e identidades de gênero (BIROLI, 2013) e os limites nos ajustes entre autonomia e responsabilidade individual (BIROLI, 2012b).
} 
as formas de subordinação legitimadas pelos contratos, em vez de avaliar o caráter voluntário do engajamento dos indivíduos nos contratos ou o grau de autonomia desses indivíduos no momento em que os contratos são firmados. O problema que se coloca é, diferentemente, que alguns contratos e acordos consistam em uma realidade na qual o indivíduo abre mão de sua liberdade futura para decidir por si mesmo (PHILLIPS, 2010, p. 122), definindo uma forma legal de obediência e renunciando ao seu autogoverno. Pode-se dizer que, desse modo, a autonomia é o valor que orienta de maneira mais abrangente a análise, em vez de ser mobilizada para avaliar o momento e a situação em que os compromissos se definem. O autogoverno excede a correspondência entre liberdade e ausência de coerção, fazendo com que o problema a ser enfrentado esteja nas formas socialmente "toleradas" de subordinação.

As análises de Carole Pateman expõem, sobretudo, a convivência entre regimes democráticos e as bases não democráticas de instituições que são centrais a essas sociedades. Destacam a contradição entre governo democrático e ausência de autogoverno nos locais de trabalho (PATEMAN, 1992; 2009) e entre governo democrático e ausência de autogoverno na vida doméstica (PATEMAN, 1988; 1989).

Na celebração dos contratos, a autonomia seria, ao mesmo tempo, pressuposta e negada (PATEMAN, 2009, p. 209). No liberalismo, os contratos e acordos são legítimos na medida em que são voluntariamente assumidos. É nesse sentido também que a obrigação política, para sua legitimidade, depende do consentimento voluntário dos indivíduos (PATEMAN, 1985), o que remete ao peso concedido à ficção de origem nas teorias contratualistas. Mas são esses mesmos contratos que permitem que a perda de autonomia, se decorrente de um ato voluntário, seja condizente com as premissas mobilizadas. Para além da centralidade do contrato em autores fundamentais para o pensamento liberal moderno, como Hobbes e Locke, e para o pensamento liberal contemporâneo, como Rawls, o liberalismo como doutrina abrangente dependeria, senão da ficção de um ato voluntário original de que todos tomariam parte como iguais, de outra ficção, a de que os indivíduos consentem voluntariamente em viver sob as normas e formas de obrigação política que os vinculam e estabelecem as relações de autoridade.

A livre-escolha é, assim, mais do que um ideal, a condição sine qua non para a legitimidade e justeza dos contratos e dos acordos. É, no entanto, porque os indivíduos são assim considerados que se pode aceitar a alienação parcial do seu direito ao autogoverno. O ponto, para Pateman, é que quando se aborda a condição, de liberdade, do indivíduo ao firmar voluntariamente o contrato, não se analisa necessariamente o grau de submissão resultante do contrato. $\mathrm{O}$ autogoverno torna-se, nessa crítica, o valor político central, em contraposição à centralidade do grau de liberdade e da avaliação do caráter voluntário da escolha do indivíduo, inclusive quando abre mão de uma parte de sua liberdade futura. Mesmo que não exista exploração em um contrato firmado voluntariamente, se ele permite relações "de domínio e subordinação em que se reduz a liberdade ou autonomia de uma das partes interessadas" (PATEMAN, 2009, p. 196) há aqui um problema do ponto de vista da construção de uma sociedade democrática.

A análise do conceito de "propriedade na pessoa" permitiria sobretudo uma abordagem crítica da condição de alienabilidade parcial da pessoa nos contratos, como mencionado anteriormente. $\mathrm{O}$ aspecto significativo nos "contratos que constituem tais relacionamentos não é uma troca, e sim a alienação de um item particular da propriedade na pessoa [...], o direito ao autogoverno" (idem, p. 181). É por meio de contratos voluntariamente firmados que se "arrenda" parte da propriedade de si, o que corresponde a reduzir a autonomia e o autogoverno de uma das partes - do trabalhador, das mulheres (idem, p. 190). É desse prisma que Pateman analisaria também os contratos de prostituição e de barriga-de-aluguel. A alienação de si, mesmo que parcial, não poderia ser objeto de transações de mercado, ainda que os agentes nessas transações sejam, dos dois lados, indivíduos livres, com direitos sobre si e com a possibilidade de fazer escolhas livres de interferências indevidas e de coerção.

$O$ fato de que a alienação seja baseada em um ato livre não é suficiente quando se considera que a subordinação, e não o caráter voluntário das escolhas, é o problema político primordial para a democracia. Nesse caso, a questão passa a ser "quais são os direitos requeridos para minimizar a subordinação e maximizar a liberdade individual, e quais são os mecanismos necessários para manter a sua efetividade" (PATEMAN, 2008, p. 241). É a perspectiva oposta ao entendimento de que o direito se define como direito à livre-escolha, como direito a engajar-se em relações, acordos e contratos, independentemente do caráter dessas relações e acordos.

A ideia de que os indivíduos relacionam-se em uma espécie de livre mercado, em que as trocas são reguladas tão somente pela garantia de que todos possam escolher livremente, elide o caráter político dos conflitos e injustiças relativos ao fato de que o 
exercício da livre-escolha por alguns, sobretudo por aqueles que estão em posição vantajosa ao realizarem suas escolhas, corresponda a restrições às escolhas "voluntárias" de outros. Os exemplos de Nozick (1974, p. 262-264) ao discutir as trocas voluntárias são bastante reveladores dos limites das abordagens focadas no engajamento voluntário em trocas e contratos. Neles, o contrato de casamento e o contrato entre proprietários e trabalhadores tornam-se correlatos, mas por razões completamente distintas daquelas que os aproximam na análise de Pateman.

O mercado do matrimônio é apresentado por Nozick a partir de um conjunto variado de alternativas, que vai reduzindo-se conforme as escolhas de alguns vão se efetivando. O fato de que eu não me case com o indivíduo que eu tinha como minha primeira opção - porque as escolhas feitas anteriormente às minhas limitaram as alternativas que tenho disponíveis -, ou escolha me casar quando (e justamente porque) a outra alternativa disponível seria manter-me solteira, não tornaria minha escolha menos voluntária. No mercado de trabalho, por sua vez, o fato de que minhas alternativas sejam trabalhar ou passar fome não tornaria minha escolha por trabalhar involuntária - no exemplo, ainda seria possível escolher entre empregos distintos. O principal, nesse caso, é que as restrições às minhas alternativas são legítimas caso resultem de ações voluntárias de outros indivíduos, que agiram nos limites dos seus direitos. Os direitos são, assim, entendidos de maneira bastante distinta daqueles "direitos requeridos para minimizar a subordinação e maximizar a liberdade individual" (PATEMAN, 2008, p. 241). Para Nozick, em uma formulação que seria, grosso modo, endossada pelas demais abordagens no libertarianismo, "a escolha que uma pessoa faz entre alternativas que são, em diferentes graus, pouco palatáveis não se torna não-voluntária pelo fato de que outros voluntariamente escolheram e agiram dentro dos limites dos seus direitos de modo que não disponibilizou, a essa pessoa, uma alternativa mais palatável" (NOZICK, 1974, p. 263). Os contratos e acordos consistem, assim, no direito de neles engajar-se com qualquer pessoa que tenha também o direito de fazê-lo (idem, p. 264). Trata-se de uma abordagem que justifica a subordinação, em nome de uma ideia de liberdade individual que convive bem com hierarquias e formas de autoridade que restringem a liberdade de grande parte dos indivíduos.

Por outro lado, o foco na exploração, em análises como as de Cohen (1995) e Ingram (1994), diminuiria o potencial da crítica aos libertarianistas e ao liberalismo igualitário (PATEMAN, 2009, p. 173). O desprezo pela subordinação como problema político e a construção das abordagens no âmbito da filosofia moral - assumindo nela a forma do "rawlsianismo metodológico"7 - resultariam na tendência contemporânea de "despolitização da teoria política" (idem, p. 175-176 | p. 198-199), no "distanciamento da política em direção à filosofia moral e à preocupação com a justiça" (idem, p. 190).

A construção da democracia corresponderia, em uma abordagem que busca justamente avançar na politização da teoria política, ao enfrentamento de dois problemas de primeira ordem: a redução da subordinação e a criação de uma sociedade mais democrática (idem, p. 174). Em outras palavras, seria preciso recolocar o foco na conexão entre "as relações de subordinação civil e os problemas referentes à autonomia e a democratização" (idem, p. 190). Mas, para isso, é necessário desnaturalizar o direito de alguns de governar sobre outros, seja por meio do emprego, que instituiria o direito do empregador de dar ordens ao empregado (o que Pateman discute, nesse caso, a partir da análise de Ellerman (1992), mas que já estava na base da crítica aos limites da democracia no seu livro Participação e teoria democrática, de 1970), seja por meio do casamento ou de outros arranjos nos quais as relações de gênero sejam marcadas por assimetrias de recursos e de autoridade (em geral, pela complementaridade entre as duas), constituindo como ordem "natural" o comando-obediência. Afastandose, nesse sentido, da tradição liberal, a posição de Pateman é que a democracia depende de uma igualdade robusta como sua base (MANSBRIDGE, 2008, p. 23).

As teorias fundadas na ideia de consentimento voluntário apresentariam, como ambiguidade fundamental, o fato de que pressupõem indivíduos igualmente livres e contribuem para justificar relações de autoridade. A ideia de que os indivíduos nascem livres e iguais leva à necessidade de justificar a razão pela qual esses mesmos indivíduos submetem-se a ser governados por outros. Essa justificativa, estabelecida de modo que não fira esses pressupostos, corresponde a um dos pilares fundamentais do

\footnotetext{
7 Pateman denomina "rawlsianismo metodológico" a pressuposição, por parte da teoria política contemporânea e, especialmente, pelas abordagens predominantes nas teorias da justiça, de que há intuições, ideias e princípios compartilhados nas sociedades democráticas e nas interpretações sobre a democracia. Instituições e interpretações são, assim, vistas como "um cabedal de ideias implicitamente compartilhado", suspendendo os conflitos e polêmicas em torno da própria noção de democracia. Com base nessa pressuposição, "a função dos teóricos políticos passa a ser, então, a de encontrar justificativas morais para interpretações já aceitas dos princípios que fazem parte de um histórico institucional admitido como verdadeiro" (PATEMAN, 2009, p. 199), eliminando a problematização de formas aceitas de autoridade.
} 
liberalismo, a noção de que as relações de autoridade são legítimas apenas se - e porque - consentidas. A noção de consentimento é, desse modo, ampliada a ponto de enfraquecer seu componente necessário para a manutenção dos próprios pressupostos do liberalismo, o caráter efetivamente voluntário do consentimento. A maior parte das compreensões contemporâneas do contrato atualizaria o entendimento de Locke de que "o consentimento das gerações futuras (ao contrato social firmado pelos seus antepassados) pode ser tomado como dado se os indivíduos seguem pacificamente o curso de sua vida cotidiana", sem a necessidade, portanto, da expressão desse consentimento (PATEMAN, 1989, p. 73). Resta, assim, o voluntarismo hipotético ou tácito, pouco exigente na compreensão do ato de consentir e ainda menos criterioso na consideração das relações daí resultantes (PATEMAN, 1988; 1989).

\section{CONSENTIMENTO, GÊNERO E VULNERABI- LIDADE SOCIALMENTE CAUSADA}

Os problemas colocados pela análise das relações entre consentimento e contrato ultrapassam as situações específicas em que as relações são pactuadas como contratos. Constrangimentos de diversos tipos definem - e restringem - as opções dos indivíduos, segundo padrões distintos que evocam sua posição nas relações sociais. $\mathrm{O}$ foco na escolha individual oculta os constrangimentos estruturais e sistemáticos que estão na base das preferências que conduzem às escolhas dos indivíduos ou que restringem as alternativas de modo a produzir escolhas que são a expressão da ausência de alternativas, e não de preferências individuais. A questão que se coloca, então, como fundamental para o feminismo é como, em sociedades nas quais os direitos foram universalizados, são definidas e reproduzidas formas de "vulnerabilidade socialmente causada e distintamente assimétrica" (OKIN, 1989, p. 138).

A partir da análise da posição das mulheres, é possível discutir os problemas que atravessam as conexões entre o consentimento na vida cotidiana e o consentimento no estado liberal-democrático ${ }^{8}$. Ainda que as relações de obrigação política no liberalismo tenham como a base de sua legitimidade o fato de serem relações consentidas - levando ao entendimento de que a obrigação política legítima corresponde à autoobrigação e de que a organização social é o produto de escolhas voluntárias - as mulheres foram declaradas

8 Cf. "Woman and Consent" (PATEMAN, 1980), republicado em Pateman (1989). O texto é, parcialmente, uma retomada de questões discutidas no capítulo 7 do livro The Problem of Political Obligation (PATEMAN, 1985). incapazes de consentir nas teorias clássicas do contrato e, por um longo tempo, nas sociedades liberais ${ }^{9}$. Mas foram, ao mesmo tempo, apresentadas como consentindo sistematicamente - por exemplo, no casamento e nas relações sexuais, que são vistas como distintas do estupro se e apenas se há consentimento voluntário, tema ao qual voltarei em breve.

Arranjos sociais em que a autoridade masculina definia as alternativas disponíveis compuseram por muito tempo a situação na qual a mulher consentia casar-se. A autoridade paterna e, em seguida, a autoridade do marido definiram limites às escolhas das mulheres e foram reforçadas pelos costumes correntes, em que as restrições ao estudo e a atividades profissionais e o estímulo ao casamento no processo de socialização acentuaram a dependência das mulheres. Ainda que as legislações tenham variado em diferentes países, é apenas a partir de meados do século $\mathrm{XX}$, no Ocidente, que as mulheres passariam a ser definidas juridicamente como indivíduos plenos direitos políticos, direito à propriedade e à titularidade de contas bancárias e o direito ao divórcio compõem esse contexto.

No casamento convencional, segundo os códigos predominantes até aproximadamente a década de 1970, no Ocidente, a mulher alienaria parte de si na medida em que concederia ao marido o controle sobre sua pessoa, o que inclui o domínio sobre seu corpo. A dualidade entre vida pública e vida doméstica contribuiu para impedir a tematização da violência doméstica e do estupro no casamento. A primeira foi, por muito tempo, tida como um problema doméstico e, em forte medida, naturalizada como parte constitutiva da relação de dominação entre homens e mulheres. O estupro no casamento, por sua vez, foi visto até recentemente como uma impossibilidade lógica, uma vez que o direito ao corpo da mulher era entendido como algo que é tranferido para o marido no momento do casamento.

As transformações nas últimas décadas levaram a uma situação, em vários países, na qual a posição de mulheres e homens no casamento se alterou. As chances efetivas de "saída" se ampliaram não apenas com a legalização do divórcio, mas, sobretudo, com o maior acesso das mulheres ao trabalho remunerado. Além disso, a diversidade dos arranjos familiares e conjugais leva a pensar de forma mais complexa no modo como afeto, vida doméstica, vida familiar,

9 A obrigação política voluntária seria, assim, apenas parcialmente relevante. A obrigação daqueles considerados incapazes, como as mulheres, as crianças e os deficientes mentais, poderia ser fundada em outras bases (idem, p. 15). 
sexualidade e poder entrelaçam-se nas sociedades contemporâneas. A formalização das relações entre uma mulher-dependente e um homem-provedor é hoje apenas uma das formas assumidas pelos arranjos conjugais, familiares e/ou afetivos (FRASER, 1997; PATEMAN, 2008) $)^{10}$.

As conquistas do feminismo na legislação relativa à violência doméstica e ao estupro apresentam-se como avanços não apenas na contenção dessas formas de agressão contra a mulher, de modo mais específico, mas também na definição do direito das mulheres à autodeterminação. As hierarquias nas duas esferas, privada e pública, potencializam uma posição de maior vulnerabilidade para as mulheres, relativamente aos homens, na medida em que restringem sua autonomia de diversas maneiras - do direito ao controle sobre seu corpo ao acesso a recursos materiais e simbólicos que viabilizam o autogoverno. $\mathrm{O}$ fato de que as mudanças na legislação convivam com a manutenção de formas cotidianas de violência representadas, entre outras, pelo alto número de estupros e de assassinatos de mulheres por homens com quem tiveram relações afetivas (mesmo que se considere como positivo o maior registro das denúncias) ${ }^{11}$, assim como o fato de que a legislação sobre a violência contra as mulheres mude enquanto não há avanço (como no Brasil) ou há retrocessos (como no caso dos Estados Unidos) na

10 Por outro lado, pesquisas realizadas em contextos diversos mostram que uma série de filtros continua a orientar e a limitar a posição de mulheres e homens na vida pública, no trabalho e na política, a partir de compreensões convencionais dos papeis sexuais, da divisão sexual do trabalho e de preferências que seriam fundadas no sexo biológico. Para análises de diferentes dimensões em que esses filtros têm impacto, em diferentes partes do mundo, conferir, entre muitas outras, Bonetti e Abreu (2011), Chun, Kim e Jo (2012), Campus (2010), Folbre (1994), Fox e Lawless (2012), Kahn (1996), Legerski e Cornwall (2010), Miguel (2008), Miguel e Biroli (2011), Paxton e Hughes (2007) e Pinheiro (2007).

11 No Brasil, a luta para consolidar a compreensão de que violência doméstica contra a mulher resulta de relações de gênero desiguais, que fez parte da atuação do movimento feminista ao longo de décadas, teve como um de seus principais resultados a aprovação da Lei n. 11340, conhecida como Lei Maria da Penha, em 2006. A lei tipifica a violência doméstica contra a mulher e cria mecanismos para combatê-la, mas o Brasil continuaria a ser um dos países em que altos índices de violência contra a mulher são sistematicamente verificados. Para uma análise dos avanços aos quais corresponde a lei, mas também das dificuldades em fazer avançar o combate à violência contra a mulher no Brasil, no âmbito institucional (por exemplo, no treinamento dos agentes nas delegacias e no poder Judiciário) e dos costumes (pela permanência de visões conservadoras das relações de gênero, que incluem a naturalização da agressividade masculina e do direito de posse sobre a mulher), cf. Bandeira, L. (2009). legislação sobre o direito das mulheres ao aborto, sinaliza que há atores políticos relevantes agindo, sistematicamente, contra a construção de relações de gênero igualitárias e, no sentido de Pateman, contra a democratização ${ }^{12}$. Sinaliza, ainda, que essas formas de violência são, em algum grau, toleradas socialmente, mantendo-se como uma "possibilidade constante no horizonte da imaginação social vigente" (YOUNG, 1990, p. 62). A violência contra as mulheres pode ser, nesse sentido, entendida como uma prática social e não individual, "sistêmica porque dirigida a membros de um grupo simplesmente porque ele são membros daquele grupo", e parte da experiência compartilhada do grupo, no sentido de que são vulneráveis à violência devido a sua identidade de grupo (idem, p. 62).

Em todos esses casos, as práticas e normas vigentes incidem, também, sobre as condições para que o processo de formação das preferências realizese de forma mais autônoma, além de terem impacto na definição das alternativas efetivas mediante as quais a ideia de escolha teria sentido - considerando aqui que incluem as condições para que as mulheres possam efetivamente participar, como pares, na construção das alternativas disponíveis.

Vários dos problemas colocados por Pateman permanecem, assim, atuais. Ainda que os aspectos datados de sua análise do contrato de casamento precisem ser revistos e rediscutidos, permanecem, especialmente, as questões relativas à relação entre contrato e subordinação no liberalismo, assim como as ambiguidades na noção de consentimento que está na sua base. No cotidiano das sociedades liberais, o não-consentimento explícito das mulheres "tem sido tomado como irrelevante ou tem sido reinterpretado como "consentimento"' (PATEMAN, 1989, p. 72). É no âmbito dessa discussão que se coloca o problema da definição das fronteiras entre consentimento e nãoconsentimento ou, em outras palavras, ganham destaque os problemas relativos à diferenciação entre as escolhas que são desdobramentos de interferências arbitrárias e aquelas que seriam legítimas, considerando que se trata de contextos permeados por relações de

\footnotetext{
12 No caso do aborto, seria possível abordar as tensões entre, de um lado, a liberdade de expressão religiosa (que tem hoje, no Brasil, na defesa do chamado "direito à vida" uma de suas formas de ação política mais sistemáticas), que corresponderia a um modo de compreender a liberdade no pensamento liberal, e o direito das mulheres à autodeterminação, que, em uma concepção como a que está sendo trabalhada aqui a partir de Carole Pateman, incluiria necessariamente o direito das mulheres ao aborto, como parte do direito inalienável a comandar seu próprio corpo.
} 
opressão. Essa discussão será feita a partir das análises das ambiguidades na noção de consentimento, quando o foco recai sobre o estupro.

\section{CONSENTIMENTO E ESTUPRO}

A distinção entre sexo consentido e sexo forçado permite avançar nos problemas de que se vem tratando neste artigo. No passado das teorias clássicas do contrato, a superfluidade do consentimento voluntário das mulheres expressava-se nos códigos que naturalizavam a agressividade masculina e a passividade feminina. O "não" proferido evocaria uma moral na qual a modéstia e a honra corresponderiam à duplicidade. Quando se estabelece que as mulheres "devem sempre dizer 'não' mesmo quando desejam dizer 'sim", como se vê de modo exemplar nas orientações distintas dadas por Rousseau a Sofia e a Emílio, a recusa em consentir é vista como algo "aparente" e que não pode, em uma mulher, ser tomado como tal (idem, p. 76).

A negação da realidade do estupro corresponde, nesse sentido, a considerar distintamente a validade do consentimento dos indivíduos, no caso de homens e mulheres. Se há, e certamente há, especificidades na violência sexual em relação a outros aspectos das hierarquias e da tolerância à subordinação nas sociedades contemporâneas, os problemas relativos ao estupro e ao consentimento expõem os limites da compreensão de que no liberalismo os indivíduos são iguais em sua liberdade e capacidade de escolher, consentindo ou recusando. $\mathrm{O}$ foco no estupro expõe uma série de razões pelas quais a oposição entre coerção e livre-escolha é insuficiente como a base para a análise das condições efetivas nas quais os indivíduos consentem ou recusam-se a consentir. As fronteiras entre coerção e livre-escolha são, principalmente, insuficientes como ponto de partida para explicações que levem em conta o que é de fato necessário para que os indivíduos sejam vistos como consentindo. São falhas, também, como prisma para o entendimento das razões pelas quais o que se requer para considerar o consentimento dos indivíduos varia de acordo com quem são, isto é, de acordo com sua posição social.

As fronteiras entre consentimento e nãoconsentimento são problemáticas e ambíguas, como se pode ver em uma série de exemplos contemporâneos. Pesquisa ampla, realizada nos Estados Unidos no início da década de 1990, constata diferenças abismais na percepção que mulheres e homens têm do sexo consentido e do sexo forçado. Enquanto 22\% das mulheres entrevistadas dizem ter em algum momento sido forçadas a alguma prática sexual, apenas 3\% dos homens dizem ter, em algum momento, usado força em suas interações sexuais com mulheres. Segundo os pesquisadores, mais do que a mentira ou a recusa a assumir o uso da força, a pesquisa revelaria que "a maioria dos homens que forçaram uma mulher a práticas sexuais não reconheceram o quanto as mulheres percebiam seu comportamento como coercivo" (Michael apud NUSSBAUM, 1999, p. 137). Nesse caso, teríamos um cenário em que desejo e preferências são distorcidos (NUSSBAUM, 1999, p. 138). Há, nesse sentido, uma continuidade entre as representações sociais hegemônicas do comportamento social "natural" a homens e mulheres, o comportamento efetivo dos homens como agressores e a distinção entre sexo forçado e sexo consentido na lei e nos julgamentos.

A negação da realidade do estupro tem sido, também, um dos eixos nos retrocessos ou no impedimento de avanços na legislação sobre o aborto (MIGUEL, 2012b). A declaração de Luiz Gonzaga Bergonzini, o bispo de Guarulhos, feita em 2011, de que "é muito difícil uma violência sem o consentimento da mulher" e que são frequentes os "casos em que não é bem violência", é exemplar ${ }^{13}$. Uma compreensão semelhante foi expressa na diferenciação entre "estupro legítimo" " "ilegítimo" feita pelo candidato republicano a uma cadeira no Senado dos Estado Unidos, Todd Akin, em 2012. No "estupro legítimo", o corpo da mulher seria capaz de naturalmente evitar uma gravidez. Do contrário, a própria gravidez indicaria que houve, em algum grau, consentimento ${ }^{14}$.

Esse tipo de distorção é bastante evidente nos processos judiciais de estupro. Manifesta-se,

13 "É muito difícil uma violência sem o consentimento da mulher, é difícil", comenta. O bispo ajeita os cabelos e o crucifixo. "Já vi muitos casos que não posso citar aqui. Tenho 52 anos de padre... Há os casos em que não é bem violência... [A mulher diz] 'Não queria, não queria, mas aconteceu...'”, diz. "Então sabe o que eu fazia?" Nesse momento, o bispo pega a tampa da caneta da repórter e mostra como conversava com mulheres. "Eu falava: bota aqui", pedindo, em seguida, para a repórter encaixar o cilindro da caneta no orifício da tampa. O bispo começa a mexer a mão, evitando o encaixe. "Entendeu, né? Tem casos assim, do 'ah, não queria, não queria, mas acabei deixando"” (Cristiane Agostini, "A fé do bispo contra os partidos”, Valor Econômico, São Paulo, p. A-16, 13.jun.2011, citado em Miguel (2012b)).

14 Ao ser questionado sobre sua posição em relação ao estupro, o candidato republicano ao Senado, ligado ao grupo conservador "Tea Party", disse que é contra o aborto, sem exceções. E que "se o estupro é legítimo, o corpo da mulher tem maneiras de buscar impedir a gravidez". Complementou sua posição explicando que nos casos em que isso não ocorre deve haver punição, mas ao estuprador e não "à criança" (ELIGON \& SCHWIRTZ, 2012). 
sobretudo, nos casos em que a crença do homem no consentimento da mulher se torna determinante no julgamento, mesmo que tenha havido sinais explícitos de que ela não consentia ${ }^{15}$. É frequente, também, nos casos em que a validade das declarações e testemunhos, assim como os critérios mobilizados para a análise das ações do acusado, variam segundo o perfil "moral" da vítima16.

Crimes sexuais (que incluem sedução, assédio, atentado violento ao pudor e tentativa de estupro) e estupro são socialmente tratados "numa perspectiva que oscila entre considerá-los crimes hediondos, principalmente quando praticados contra crianças, ou como fatos banais", em variações orientadas por julgamentos morais, segundo a "imagem que se faz da vítima" (OLIVEIRA et alii, 2005, p. 377). A relação entre honestidade, bons costumes e validade das declarações incide diretamente sobre o modo como são traçadas as fronteiras entre consentimento voluntário, consentimento tácito e sexo forçado. O duplo padrão de conduta sexual e a divisão das mulheres entre castas e não castas faz com que o consentimento seja mobilizado de maneiras distintas, colaborando para que a violência sexual masculina seja percebida como algo normal (MACKINNON, 1987; 2005; DWORKIN, A., 1997). Aqui, também, é possível elencar uma série de exemplos, além dos processos judiciais, que indicam que essas compreensões atravessam e organizam as percepções, contemporaneamente. Em piadas como a do comediante brasileiro Rafinha Bastos em seus standup shows, em 2011, dizendo que as mulheres feias deviam agradecer quando são estupradas ${ }^{17}$, ou em declarações como a do policial canadense, em Toronto,

15 O caso mais citado na literatura é Regina v. Morgan (House of Lords, Inglaterra, 1976), em que os estupradores teriam sido informados, pelo marido da vítima, que a luta e a recusa de sua mulher eram sua forma regular de demonstrar excitação. A crença dos estupradores no consentimento da vítima poderia, assim, ser tomada como "não razoável" mas "honesta" (são os termos usados no processo). Os homens nesse caso poderiam ser vistos como estúpidos ou negligentes, mas não como culpados de estupro como equivalente a sexo não-consentido (cf. discussão em PATEMAN, 1989, p. 80-81). As reações a esse julgamento levaram a mudanças na lei sobre estupro na Inglaterra e tiveram impacto também em decisões nas cortes dos Estados Unidos (cf. NUSSBAUM, 1999, p. 138).

16 Casos assim são relatados amplamente na literatura sobre gênero e estupro e podem ser observados também nos estudos do contexto brasileiro feitos por Ardaillon e Debert (1987), Bandeira e Almeida (2005), Debert e Gregori (2008) e Collouris (2009; 2010). Um dos corolários nesse caso é o entendimento de que "uma mulher sexualmente ativa com outros terá relações sexuais com qualquer um” (NUSSBAUM, 1999, p. 141).

17 "Toda mulher que eu vejo na rua reclamando que foi estuprada é feia pra caralho. [...] Tá reclamando do quê? Deveria mais uma vez em 2011, de que as mulheres deveriam parar de se vestir como "vadias" para evitar estupros ${ }^{18}$, temos variações de expressões que poderiam ser tomadas como exceções folclóricas ou extremistas se não fossem parte de um conjunto amplo e difuso de representações sobre mulheres e homens que naturalizam a violência sexual.

Para avançar na direção oposta, o consentimento precisaria ser claramente distinto da recusa a consentir. O "não" deve ser sempre tomado como expressão de recusa - "quando um indivíduo diz 'sim' ou 'não', não importa quem pronuncia essas palavras, a presunção deve ser sempre a de que o indivíduo quis dizer o que ele ou ela disse" (PATEMAN, 2008, p. 237). Isso evitaria "o aspecto mais trágico" do problema relativo a mulheres, estupro e consentimento, que é o entendimento de que o estupro é "uma expressão extrema, ou uma extensão, da relação 'natural' entre homens e mulheres” (PATEMAN, 1989, P. 82).

Mas outras questões e problemas colocam-se quando se discute o fato de que essa posição pressupõe que exista a possibilidade concreta de recusar-se a consentir. Mais uma vez, deslocando o problema da oposição entre livre-escolha e coerção, quando se coloca como aspecto central as condições efetivas para que seja possível recusar-se a consentir, as relações de poder e as formas de opressão e dominação existentes é que se tornam o foco para a análise da produção das preferências e do que está envolvido na escolha dos indivíduos - do que conduz a determinadas escolhas, das consequências dessas escolhas. Ganham destaque, nesse caso, os limites concretos para a "saída" e a recusa, assim como as preferências adaptativas que são desenvolvidas em situações nas quais os custos sociais da recusa a padrões convencionais é muito alto (SUNSTEIN, 2009, p. 228). O "sim" é que se torna, então, objeto de escrutínio crítico.

Recorre-se, rapidamente, a outro exemplo que parece útil para expor os matizes do "sim" e as razões para que seja tomado como objeto da crítica feminista. Um episódio do seriado americano Lie to me trata de uma denúncia de estupro em um batalhão do Exército

dar graças a Deus. Isso pra você não foi um crime, e sim uma oportunidade. [...] Homem que fez isso [...] não merece cadeia, merece um abraço" (RODRIGUES, 2011). Para uma análise desse caso focada nos problemas relativos à liberdade de expressão, cf. Miguel (2012a).

18 A declaração deu origem à "Slot walk", que aconteceu pela primeira vez na cidade de Toronto e repetiu-se em diversas cidades do mundo nos anos de 2011 e 2012. No Brasil, foi nomeada pelas participantes "Marcha das vadias". 
estadunidense que atuava no Afeganistão. O ponto, para esta discussão, é que a trama leva a uma recruta que havia desertado por não suportar mais o relacionamento com seu comandante. Esse relacionamento era, no entanto, visto por seus colegas homens como um namoro, como uma relação consentida. A partir do depoimento da desertora, é definida a perspectiva no episódio. O comandante do seu batalhão a havia procurado em sua tenda, na missão no Afeganistão, e ela consentiu com a relação sexual que ocorreu, e ocorreria durante o tempo em que lá estiveram, por duas razões: ele era seu superior hierárquico e poderia prejudicá-la; a forma de prejudicar desafetos era colocálos na linha de frente dos comboios, em uma posição de alto risco. A visão da recruta é chancelada pelo episódio, não por um julgamento fundado na veracidade de sua versão - a recruta é, na realidade, levada a nomear como estupro o sexo consentido em decorrência do medo, para que o processo possa levar à condenação do comandante. A perspectiva do episódio baseia-se em um julgamento moral sobre o consentimento: "se não existe a possibilidade de dizer não, não é consentimento, é estupro"19.

Este é um argumento central à posição de Catharine Mackinnon, certamente a mais polêmica, e sem dúvida uma das mais influentes, entre as teóricas e militantes feministas nas últimas décadas. Para Mackinnon, o "não" das mulheres vem sendo de fato negligenciado no cotidiano das relações entre mulheres e homens (em que a objetificação e a violência seriam regra e não exceção), nos ambientes de trabalho (constituindo a problemática que levaria à criminalização do assédio sexual) e no exercício continuado da violência sexual (constituindo a posição favorável à restrição da produção e circulação de material pornográfico, uma vez que a violência contra as mulheres é vista como o fundamento da pornografia e como dela derivada, retrospectivamente).

O problema para o qual Mackinnon chama a atenção, e que caracteriza de fato sua análise, é que em um contexto no qual as relações de gênero são violentas e opressivas, em um contexto no qual há dominação, os livres atos de concordância podem não ser mais do que um efeito do medo e da ausência de alternativas. O "sim", nesse caso, não corresponderia necessariamente à expressão do consentimento voluntário.

\footnotetext{
19 Afirmação feita pelo Dr. Lightman no episódio "Concessão moral", da primeira temporada (2009) de Lie to me. Todos os episódios da série giram em torno da distinção entre verdade e mentira, por meio da leitura feita por especialistas em expressões microfaciais.
}

Na análise de Pateman, o ponto central é que é preciso dar validade ao "não" para que as mulheres sejam consideradas como indivíduos, isto é, tenham suas escolhas respeitadas e seus direitos básicos como o direito ao seu próprio corpo - garantidos. Negligenciar a expressão das mulheres, como se fosse a expressão tortuosa de um código de conduta baseado na dupla moral sexual, corresponderia a naturalizar uma condição moral e jurídica subalterna para as mulheres, naturalizando a violência masculina, como já foi dito. E isso prevalece mesmo quando se considera que existem problemas nessas escolhas, isto é, que elas podem estar baseadas em preferências "deformadas" pela dominação, podem decorrer da ausência de alternativas ou podem produzir relações de comando-subordinação, ampliando a vulnerabilidade das mulheres.

A análise de Mackinnon apresenta pontos comuns à de Pateman $^{20}$. Mas o que ressalto, nela, é o fato de que considera as continuidades, e não as rupturas, entre as seguintes situações: (i) a violência é imposta como violência - estupro e humilhação são componentes "regulares" do sexo heterossexual, são práticas que não apenas são fundadas na desigualdade, como a expressam; (ii) a violência é suportada hierarquias e formas variadas de exercício da dominação tornam o custo social da denúncia e da "saída" alto demais ou a inviabilizam; (iii) a violência não é percebida como violência - as categorias da dominação sobrepõem-se à experiência das mulheres, de tal modo que a erotização da dominação não é exclusiva da perspectiva masculina.

No primeiro caso, trata-se da recusa em considerar o não-consentimento como um limite ou de um modo de objetificação que torna o consentimento irrelevante ${ }^{21}$. As mulheres não seriam vistas como agentes, mas sim resumidas a corpos ou parcelas

20 Para uma análise mais detida da abordagem de Catharine Mackinnon, cf. Biroli (2013).

21 Em um passo adiante relativamente aos exemplos dados anteriormente, um vídeo publicado em maio de 2010, no blog humorístico "Testosterona", na página da MTV Brasil, traz conselhos a um rapaz para que ele consiga fazer sexo anal com sua namorada. Como as tentativas em que o consentimento dela era necessário não tiveram sucesso, a orientação é que dê uma tijolada na sua cabeça e tenha relações sexuais enquanto ela está desacordada. Como no caso de Rafinha Bastos, mencionado antes, o humor, alega-se, permitiria que esse tipo de abordagem do tema não configurasse adesão, isto é, defesa do estupro. Mesmo assim, o site foi retirado do blog depois da solicitação da Secretaria de Políticas para Mulheres para que fosse investigado, pelo Ministério Público, por conter apologia ao estupro. Com a referência ao site Testosterona, cf. "Como conseguir sexo anal com sua namorada. Um vídeo educativo 
desses corpos disponíveis para o "uso" masculino. E isso ocorreria "porque são mulheres", isto é, é o fato de serem mulheres que define sua posição nas relações de opressão (MACKINNON, 2005, p. 29). Ainda que existam diferenças de ênfase e nos objetivos nas duas discussões, esse é o enfoque de Mackinnon que mais se aproxima da abordagem sobre a relação entre mulheres, consentimento e estupro em Carole Pateman.

O segundo caso é justamente aquele que procurei exemplificar com o episódio mencionado da série Lie to me. Trata-se de uma situação na qual as hierarquias existem e são visíveis, e na qual a dominação é exercida por meio de ameaças, explícitas ou veladas, e do risco permanente de prejuízo para aquelas que estão em posição de maior vulnerabilidade. Pode ser relacionado a uma série de situações que fizeram parte das análises e das propostas de lei sobre o assédio sexual, definido como "pressão sexual imposta a alguém que não está em uma posição econômica que lhe permita recusar" (MACKINNON, 1987, p. 103)22.

O terceiro caso, no entanto, é aquele que expõe os maiores problemas e, ao mesmo tempo, os desafios que podem ser mais interessantes para a teoria política. São, aliás, as questões relevantes que se colocam quando se leva a análise de Mackinnon a sério, mas são também as razões que impedem que se leve Mackinnon a sério até o fim, isto é, que colocam limites à concordância com sua argumentação, na perspectiva aqui assumida. Voltando ao primeiro dos três casos elencados, para Mackinnon a dominação e as hierarquias de gênero estão na base dos processos de objetificação. O que define o terceiro caso é que as experiências dos homens os levariam a estabelecer uma conexão entre desejo, dominação e instrumentalização - mas as experiências das mulheres, construídas nesses mesmos contextos, as levariam a compartilhar essa percepção, erotizando também a dominação. As hierarquias que estão na base dessa situação, assim como suas consequências, são, porém, distintas para mulheres e homens.

Um dos aspectos dessa análise, que explica novamente a importância da pornografia na militância e na teoria de Mackinnon, é que, para ela, as

que desmistifica essa façanha!", 15 de maio de 2010. Disponível em: http://www.testosterona.blog.br/2013/07/11/comoconseguir-sexo-anal-com-sua-namorada/. Acesso em: 22.ago.2013.

22 A demanda jurídica que esteve na base das leis do assédio nos Estados Unidos é, por sua vez, definida como "a ideia de que a lei deveria ver [o assédio sexual] da maneira que as vítimas o vêem" (MACKINNON, 1987, p. 103). desigualdades sociais são criadas e impostas por meio de palavras e imagens, que dão sentido às hierarquias sociais: "Você aprende que a linguagem não pertence a você, que você não pode usá-la para dizer o que você sabe, que o conhecimento não é o que você aprende a partir da sua própria vida, que a informação não se define a partir da sua experiência [...] você desenvolve uma identidade que é agradável e subserviente e imitativa, agressivamente passiva e silenciosa - você aprende, em uma palavra, a feminilidade" (MACKINNON, 1993, p. 6-7).

A restauração da autonomia das mulheres dependeria do enfrentamento dos múltiplos fatores, já mencionados, que impediriam que exista, de fato, consentimento voluntário. E isso requer, para Mackinnon, a criminalização das ações mas, também, a determinação de limites à expressão de discursos que seriam, eles mesmos, uma forma de abuso sexual e que, por outro lado, privariam as mulheres de expressão, especialmente da expressão contra o abuso sexual (idem, p. 9).

A tensão entre realidade "própria", realidade aprendida e realidade enunciada está, assim, permanentemente presente. Com ela, os problemas relativos às preferências adaptativas tornam-se incontornáveis para a teoria e a prática política orientadas normativamente pela valorização da autodeterminação dos indivíduos. Não se trata mais apenas - e não quero com isso dizer que esses sejam problemas menores - de distinguir consentimento de não-consentimento ou de expor o fato de que o nãoconsentimento das mulheres tenha sido e seja ainda tomado, em diversas circunstâncias, como consentimento. Trata-se de avaliar criticamente as preferências que estão na base das escolhas e do consentimento em contextos nos quais as hierarquias "funcionam", isto é, em contextos permeados por formas sistemáticas de opressão e de dominação.

Assim, quando se desloca o problema da exigência de distinção entre consentimento e recusa para o escrutínio crítico do "sim", isto é, para uma análise crítica do consentimento das mulheres - justamente porque se pressupõe que ele possa corresponder ao medo e à expressão de preferências derivadas da dominação-subordinação - uma série de novos problemas se apresenta. Um deles é que o reconhecimento de que as mulheres são agentes na reprodução da dominação masculina poderia levar, no limite, a invalidar suas preferências e suas escolhas (BIROLI, 2013). Há, por exemplo, o risco de, por meio da vitimização, ignorar as perspectivas das próprias mulheres, desconsierando-nas como indivíduos capazes de definir suas preferências e de 
realizar escolhas legítimas. Em outras palavras, existe o risco de ampliar o peso das relações de opressão e de dominação a ponto de se definir aquelas que estão em posição de desvantagem nessas relações - no caso, as mulheres - como efeito da própria dominação e, portanto, como agentes menos do que capazes ou incapazes de se autodeterminar.

A constatação de que as formas sistemáticas de opressão e de dominação incidem diretamente no processo de formação das preferências, de um lado, e nas escolhas que são feitas pelos indivíduos, de outro, não depende, no entanto, da suposição de que aquelas que estão em posição desvantajosa têm um déficit cognitivo, um déficit na compreensão de quem são e de qual é sua posição nas relações de poder. Em outras palavras, a crítica pode considerar que as mulheres estão em posição desvantajosa no processo de produção das preferências nas sociedades contemporâneas sem defini-las como vítimas incapazes de perceber mecanismos sociais que constroem essa desvantagem. Algumas das críticas a Catharine Mackinnon, elaboradas de dentro do debate feminista, incorrem nesse equívoco porque não diferenciam a denúncia de que as mulheres estão em desvantagem na produção das preferências da vitimização dessas mesmas mulheres. É o caso de Badinter (2005), para quem as análises da sexualidade na linha de Mackinnon colocam a mulher em uma posição de vítima e definem sua defesa como defesa jurídica da vulnerabilidade e da inocência diante da violência e dominação masculinas. Elas promoveriam estereótipos convencionais ao constrastar a agressividade masculina a uma espécie de pureza feminina, que existiria sob o véu da dominação. Mansbridge (2008, p. 19) afirma, na mesma direção, que "os movimentos de mulheres do final dos anos 1960 e do início dos anos 1970, a partir da problematização no Marxismo, argumentaram que os membros dos grupos subordinados têm probabilidades ainda menores do que outros de ter preferências que refletem o que um indivíduo mais consciente e menos oprimido pensaria ser melhor para eles".

Há, de fato, limites na aposta mackinnoniana focada na intervenção jurídico-estatal para a proteção das mulheres, em sociedades sexistas. Mas é preciso compreender que sua análise discute mecanismos sociais que invalidam as experiências das mulheres e que, com isso, bloqueiam a produção e profusão de preferências autônomas, que desafiam as preferências que respaldam a dominação masculina. $\mathrm{Na}$ compreensão de Mackinnon, há uma espécie de voz sob a voz, que precisaria ser resgatada, um recurso à conscientização que passa pela recuperação da experiência compartilhada das mulheres. A consciência da dominação e das desvantagens, e sofrimentos implicados em sua posição social, viria da ressignificação, pelas próprias mulheres, da experiência compartilhada da subordinação e da violência. Daí a aposta de Mackinnon nos grupos de mulheres (MACKINNON, 1989, p. 90). A dominação não totaliza as experiências, portanto, mas sua análise, como a de Pateman, alerta para o fato de que há obstáculos para que as perspectivas daqueles que estão em posição de desvantagem tenham validade social e política. Por isso a formação e a reprodução de preferências que justificam o status quo e naturalizam as hierarquias se torna um problema político de primeira ordem.

\section{CONCLUSÕES}

Nas análises aqui consideradas, as assimetrias no controle dos recursos para formação das preferências são um problema central para a democracia. Tornase relevante compreender quem controla os recursos para a produção e circulação de discursos que estimulam determinadas compreensões, concepções e hábitos, estimulando nesse processo a formação de determinadas preferências e colaborando para tornar outras menos visíveis, menos expressivas socialmente.

Preferências, escolhas, consentimento e recusa a consentir remetem diretamente às posições concretas dos indivíduos, às assimetrias socialmente estruturadas e às alternativas efetivamente disponíveis. O que está em jogo é "o reconhecimento do direito de uma mulher à escolha autônoma" (NUSSBAUM, 1999, p. 143). O direito ao autogoverno depende, entre outras coisas, da distinção entre consentimento voluntário, consentimento tácito, aquiescência e recusa. Do mesmo modo, a distinção entre preferências autônomas e preferências adaptativas torna-se um tópico central para a crítica às formas socialmente toleradas de subordinação.

Mas há componentes distintos nas análises aqui discutidas. Varia o próprio entendimento dos fatores que limitam as escolhas ou legitimam engajamentos que conduzem à subordinação. Enquanto Carole Pateman volta-se, predominantemente, para a crítica aos acordos, contratos e práticas sociais que produzem relações de comando e subordinação - analisando, sobretudo, sua acomodação no pensamento e nas instituições liberais -, Catharine Mackinnon concentra-se nas formas de violência que se produzem e são justificadas a partir das desigualdades existentes nas democracias. Para ela, nessa perspectiva, o enfrentamento das desigualdades corresponderia, entre outras coisas, a combater os processos por meio dos quais é incentivada a formação de preferências "deformadas" pela dominação. Seria preciso um 
escrutínio crítico das preferências atualmente existentes - inclusive daquelas assumidas pelas próprias mulheres em circunstâncias nas quais prevalecem as desigualdades de gênero - para tornar possível a produção de preferências autônomas e a construção de relações mais democráticas.

Sem desconsiderar os limites dessas análises, elas definem problemas para a teoria e a prática democrática que não seriam visíveis, ou seriam visíveis de formas distintas, sem a crítica feminista à dualidade públicoprivado. Do mesmo modo, é a análise crítica da relação entre preferências, autonomia e desigualdades de gênero que permite avançar em reflexões que, construídas desse ponto de partida, ultrapassam a especificidade das formas de dominação e opressão nas relações de gênero. São abordagens para as quais a democracia depende da desnaturalização do direito de alguns de comandar outros, da desnaturalização da subordinação.

Flávia Biroli (flaviabiroli@gmail.com) é Professora do Instituto de Ciência Política da Universidade de Brasília (UnB) e pesquisadora do CNPq.

\section{REFERÊNCIAS BIBLIOGRÁFICAS}

AGOSTINI, C. 2011. A fé do bispo contra os partidos. Valor Econômico, São Paulo, p. A-16, 13.jun.

ARDAILLON, D. \& DEBERT, G. 1987. Quando a vitima é mulher: análise de julgamentos de crimes de estupro, espancamento e homicídio. Brasília: Conselho Nacional dos Direitos da Mulher.

BADINTER, E. 2005. Rumo equivocado: o feminismo e alguns destinos. Rio de Janeiro: Civilização Brasileira.

BANDEIRA, L. 2009. Três décadas de resistência feminista contra o sexismo e a violência feminina no Brasil: 1976 e 2006. Sociedade e Estado, Brasília, v. 24, n. 2, p. 401-438, maio-ago. Disponível em: http://www.scielo.br/pdf/se/v24n2/ 04.pdf. Acesso em: 22.ago.2013.

BANDEIRA, L.;ALMEIDA, T. M. C. \& MENEZES, A. M. 2005. (orgs.). Políticas públicas e violência de gênero: uma discussão com base na rotina das Delegacias Especializadas de Atendimento à Mulher (DEAMs) da região Centro-Oeste. Cadernos Agende, Brasília, v. 5, p. 35-50, dez. Disponível em: http://agende.org.br/docs/File/publicacoes/ cadernos/CadernoAgende5.pdf. Acesso em: 22.ago.2012.

BIROLI, F. 2010. Gênero e família em uma sociedade justa: adesão e crítica à imparcialidade no debate contemporâneo sobre justiça. Revista Sociologia e Política, Curitiba, v. 18, n. 36, p. 51-65, jun. Disponível em: http://www.scielo.br/pdf/rsocp/ v18n36/05.pdf. Acesso em: 21.ago.2013.

2012a. Agentes imperfeitas: contribuições do feminismo para a análise das relações entre autonomia, preferências e democracia. Revista Brasileira de Ciência Política, Brasília, n. 9, p. 738, set.-dez. Disponível em: http://www.scielo.br/ pdf/rbcpol/n9/01.pdf. Acesso em: 21.ago.2013.

. 2012b. Autonomia, responsabilidade e desigualdades no debate contemporâneo sobre justiça. Trabalho apresentado no $8^{\circ}$ Encontro da ABCP, realizado em Gramado, de 1 a 4 de agosto. Digit.

2013. Autonomia, opressão e identidades: a ressignificação da experiência na teoria política feminista. Revista Estudos Feministas, Florianópolis, v. 21, n. 1, p. 81-105. Disponível em: https://periodicos.ufsc.br/index.php/ref/article/ download/29117/24641. Acesso em: 23.ago.2013.

BLACK, P. 2004. The Beauty Industry: Gender, culture, pleasure. New York: Routledge.

BONETTI, A. \& ABREU, M. A. (orgs.). 2011. Faces da desigualdade de gênero e raça no Brasil. Brasília: IPEA.

CAMPUS, D. 2010. Political Discussion, Views of Political Expertise and Women's Representation in Italy. European Journal of Women's Studies, Thousand Oaks, v. 17, n. 3, p. 249-267, Aug.

CHUN, K. O.; KIM, Y. L. \& JO, J. I. 2012. The Change of Women's Social Status in Korea: Progress and reaction. Trabalho apresentado no $22^{\circ}$ World Congress - International Political Science Association (IPSA), realizado em Madri, de 8 a 12 julho. Digit.

COLlOURIS, D. G. 2009. Novas demandas, antigos critérios: a lógica da justiça criminal nos casos de estupro. Trabalho apresentado no $33^{\circ}$ Encontro da Anpocs, realizado em Caxambu (MG), de 26 a 30 de outubro. Digit.

. 2010. A desconfiança em relação à palavra da vítima e o sentido da punição nos processos judiciais de estupro. São Paulo. Tese (Doutorado em 
Sociologia). Universidade de São Paulo.

CORNELL, D. 1998. At the Heart of Freedom: Feminism, sex, and equality. Princeton: Princeton University.

COHEN, G. H. 1995. Self-Ownership, Freedom, and Equality. Cambridge (UK): Cambridge University.

DEBERT, G. \& GREGORI, M. F. 2008. Violência e gênero: novas propostas, velhos dilemas. Revista Brasileira de Ciências Sociais, São Paulo, v. 23, n. 66, p. 165-185. Disponível em: http:// socialsciences.scielo.org/pdf/s_rbcsoc/v4nse/ scs_02.pdf. Acesso em: 23.ago. 2013 .

DWORKIN, A. 1997. Life and Death. New York: The Free Press.

DWORKIN, R. 2005. Virtude soberana. São Paulo: M. Fontes.

ELLERMAN, D. P. 1992. Property and Contract in Economics: The case for economic democracy. Oxford: Blackwell.

ELIGON, J. \& SCHWIRTZ, M. 2012. Senate Candidate Provokes Ire With 'Legitimate Rape' Comment. The New York Times, "Politics", 19.ago. Disponível em: http://www.nytimes.com/2012/08/ 20/us/politics/todd-akin-provokes-ire-withlegitimate-rape-comment.html. Acesso em: 22.ago.2013.

ELSHTAIN, J. B. 1981. Public Man, Private Woman: Women in social and political thought. Princeton: Princeton University.

ELSTER, J. 2000. Ulysses Unbound. Cambridge (UK): Cambridge University.

FOLBRE, N. 1994. Who Pays for the Kids: Gender and the structures of constraint. London: Routledge.

FOX, R. \& LAWLESS, J. L. 2012. Entrando na arena: gênero e a decisão de concorrer a um cargo eletivo. Revista Brasileira de Ciência Política, Brasília, n. 8, p. 129-164, maio.-ago. Disponível em: http:// www.scielo.br/pdf/rbcpol/n8/06.pdf. Acesso em: 22.ago.2013.

FRASER, N. 1997. Beyond the Master/Subject Model: On Carole Pateman's "The Sexual Contract". In: . Justice Interruptus: Critical reflections on the "postsocialist" condition. New York: Routledge.

HELD, V. (ed.). 1995. Justice and Care: Essential readings in feminist ethics. Oxford: Westview.

INGRAM, A. 1994. A Political Theory of Rights. Oxford: Oxford University.
KAHN, K. F. 1996. The Political Consequences of Being a Woman. New York: Columbia University.

KYMLICKA, W. 1995. Multicultural Citizenship. Oxford: Oxford University.

2007. Multicultural Odysseys: Navigating the new international politics of diversity. Oxford: Oxford University.

LEGERSKI, E. M. \& CORNWALL, M. 2010. Working-Class Job Loss, Gender, and the Negotiation of Household Labor. Gender \& Society, Thousand Oaks, v. 24, n. 4, p. 447-474, Aug.

MACKINNON, C. A. 1987. Feminism Unmodified. Cambridge (MA): Harvard University.

1989. Toward a Feminist Theory of the State. Cambridge (MA): Harvard University.

1993. Only Words. Cambridge (MA): Harvard University.

2005. Women's Lives, Men's Laws. Cambridge (MA): Harvard University.

MANSBRIDGE, J. 2008. Carole Pateman: Radical liberal? In: O’NEILL, D. I.; SHANLEY, M. L. \& YOUNG, I. M. (eds.). Illusion of Consent: Engaging with Carole Pateman. University Park: The Pennsylvania State University.

MIGUEL, L. F. 2008. Political Representation and Gender in Brazil. Bulletin of Latin American Research, Oxford, v. 27, n. 2, p. 197-214, Apr.

2012a. Rafinha e a calcinha: a expressão pública, seus limites e os limites dos limites. Trabalho apresentado no XXI Encontro Anual da Compós, realizado em Juiz de Fora (MG), de 12 a 15 de junho. Digit.

2012b. Aborto e democracia. Revista Estudos Feministas, Florianópolis, v. 20, n. 3, p. 657-672, set.-dez. Disponível em: https://periodicos.ufsc.br/ index.php/ref/article/download/27651/23819. Acesso em: 22.ago.2013.

.2013c. Paternalismo e antipaternalismo na produção das preferências. Trabalho apresentado no IV Simpósio de Teoria Política do IFCS-UFRJ - Teoria, discurso e ação política, realizado no Rio de Janeiro, de 12 e 13 de setembro. Digit.

MIGUEL, L. F \& BIROLI, F. 2011. Caleidoscópio convexo. São Paulo: Unesp.

NOZICK, R. 1974. Anarchy, State, and Utopia. New York: Basic.

NUSSBAUM, M. C. 1999. Sex and Social Justice. New York: Oxford University. 
OKIN, S, M. 1989. Justice, Gender, and the Family. New York: Basic.

. 1999. Is Multiculturalism Bad for Women? In: COHEN, J.; HOWARD, M. \& NUSSBAUM, M. (eds.). Is Multiculturalism Bad for Women? Susan Moller Okin with respondents. Princeton: Princeton University.

OLIVEIRA, E. M.; BARBOSA, R. B.; MOURA, A. A. V. M.; KOSSEL, K. V.; MORELLI, K.; BOTELHO, L. F. F. \& STOIANOV, M. 2005. Atendimento às mulheres vítimas de violência sexual: um estudo qualitativo. Revista de Saúde Pública, São Paulo, v. 39, n. 3, p. 376-382. Disponível em: http://www.scielo.br/pdf/rsp/ v39n3/24790.pdf. Acesso em: 22.ago.2013.

PATEMAN, C.1980. Women and Consent. Political Theory, Thousand Oaks, v. 8, n. 2, p. 149-168, May. Disponível em: http://www.rationalitescontemporaines.paris-sorbonne.fr/IMG/pdf/ Pateman.pdf. Acesso em: 22.ago.2013.

1985. The Problem of Political Obligation: A critique of liberal theory. Berkeley: University of California.

1988. The Sexual Contract. Stanford: Stanford University.

. 1989. The Disorder of Women. Stanford: Stanford University.

1992. Participação e teoria democrática. Rio de Janeiro: Paz e Terra.

2008. Afterword. In: O'NEILL, D.; SHANLEY, M. L. \& YOUNG, I. M. (eds.). Illusion of Consent: Engaging with Carole Pateman. University Park: The Pennsylvania State University.

2009. Soberania individual e propriedade na pessoa. Revista Brasileira de Ciência Politica, Brasília, n. 1, p. 171-218, jan.-jun. Disponível em: http://seer.bce.unb.br/index.php/rbcp/article/ viewFile/6597/5322. Acesso em: 21.ago.2013.

PAXTON, P. \& HUGHES, M. M. 2007. Women, Politics, and Power: A global perspective. Los Angeles: Pine Forge.
PINHEIRO, L. 2007. Vozes femininas na politica: uma análise sobre mulheres parlamentares no pósConstituinte. Brasília: Secretaria Especial de Políticas para Mulheres.

PHILLIPS, A. 1999. Which Equalities Matter? Cambridge (UK): Polity.

2006. 'Really' Equal: Opportunities and autonomy. Journal of Political Philosophy, Oxford, v. 14, n. 1, p. 18-32, Mar. Disponível em:http://eprints.lse.ac.uk/16831/1/ReallyEqual OpportunitiesandAutonomy\%28LSERO\%29.pdf. Acesos em: 21.ago.2013.

2007. Multiculturalism without Culture. Princeton: Princeton University. Polity.

2010. Gender and Culture. Cambridge (UK):

RODRIGUES, A. 2011. A graça de um herege. Rolling Stone, São Paulo, n. 56. Disponível em: http:// rollingstone.uol.com.br/edicao/56/a-graca-de-umherege. Acesso em: 22.ago.2013.

SUNSTEIN, C. R. 1999. Should Sex Equality Law Apply to Religious Institutions? In: COHEN, J.; HOWARD, M. \& NUSSBAUM, M. (eds.). Is Multiculturalism Bad for Women? Susan Moller Okin with respondents. Princeton: Princeton University.

2009. Preferências e política. Revista Brasileira de Ciência Política, Brasília, n. 1, p. 219-254, jan.-jun. Disponível em: http://seer.bce.unb.br/ index.php/rbcp/article/viewFile/6598/5323. Acesso em: 21.ago.2013.

WOLF, N. 2002. The Beauty Myth: How images of beauty are used against women. New York: Harper Perennial.

YOUNG, I. M. 1990. Justice and the Politics of Difference. Princeton: Princeton University. .2011. Responsability for Justice. Oxford: Oxford University. 
DEMOCRACY AND TOLERANCE TO SUBORDINATION: FREE-CHOICE AND CONSENT IN FEMINIST POLITICAL THEORY.

\section{Flávia Biroli}

The text presents and analyses feminist critics to the adjustments between the liberal value of individual free-choice and material and symbolic iniquities that restrain individual autonomy. The focus is primarily a critical analysis of voluntary consent, a basic notion to liberalism. The aspects related to consent and rape are discussed to expose the limits of the liberal duality between coertion and free-choice. Departing from gender relations and the vulnerabilities that concern women's social position, it is possible to have a better understanding of the connections between consent in liberal societies' day-by-day life and consent in liberaldemocratic State. These analyses result in a desplacement of the focus, from the expression of preference and choice as voluntary acts, to self-determination as a primary value to democracy. Two sets of issues are, therefore, considered: those emerging from situations in which the differences between consent and nonconsent are nullified - nullifying also individual's moral agency - and those emerging from situations in which consent exists, but leads to subordination or deepens individual vulnerability.

KEYWORDS: consent; free-choice; rape; preferences; feminist political theory. 